\title{
A SIMPLE AND RAPID METHOD OF SAMPLE PREPARATION FROM CULTURE FILTRATE OF $M$. TUBERCULOSIS FOR TWO-DIMENSIONAL GEL ELECTROPHORESIS
}

\author{
Gavish Kumar $^{1}$, Hari Shankar ${ }^{1}$, Deepa Bisht ${ }^{2}$, Prashant Sharma ${ }^{2}$, Neelja Singhal ${ }^{2}$, V.M. Katoch ${ }^{3}$, Beenu Joshi ${ }^{1 *}$ \\ ${ }^{1}$ Department of Immunology, National JALMA Institute for Leprosy and Other Mycobacterial Diseases (ICMR), Tajganj, Agra \\ 282 001(India); ${ }^{2}$ Department of Biochemistry, National JALMA Institute for Leprosy and Other Mycobacterial Diseases (ICMR), \\ Tajganj, Agra 282 001(India); ${ }^{3}$ Department of Health Research and Director-General, Indian Council of Medical Research, Ansari \\ Nagar, New Delhi 110029 (India).
}

Submitted: January 29, 2009; Returned to authors for corrections: May 06, 2009; Approved: November 07, 2009.

\begin{abstract}
Sample preparation for Two-dimensional gel electrophoresis (2DE) is tedious and not sufficient to provide a comparative profile of secreted proteins for various strains of M. tuberculosis. High lipid content in mycobacteria limits the use of common methods as it can hinder the 2DE run. This study highlights the significance of SDS-TCA procedure over common used methods for the preparation of sample from culture filtrate as well as other proteinaceous fluids.
\end{abstract}

Key words: Culture filtrate proteins, M. tuberculosis, SDS-TCA procedure, Two-dimensional gel electrophoresis

Culture filtrate proteins (CFPs) or secretory proteins of $M$. tuberculosis have been reported to be immunodominant. Therefore, CFPs can be used as early diagnostic markers and therapeutic reagents for tuberculosis $(15,16)$, and various in vitro and in vivo experiments have evidenced the potential of secretory proteins $(8,18)$.

Two-dimensional gel electrophoresis (2DE) is an extremely powerful tool to dissect multiprotein complexes. No other technique can resolve so many protein subunits in a single operation, which is possible by 2DE. In addition, 2DE can provide an array of extremely pure proteins for amino acid sequence analysis (7) or antibody production (3). Sample preparation has been emphasized as a crucial step for successful 2DE (17). Proteins are usually secreted at low concentrations in the culture media, which makes their recovery difficult. In addition, culture media are rich in salts and other compounds interfering with most proteomics techniques. Due to lack of a simple and rapid protocol for sample preparation the studies using culture filtrate proteins of M. tuberculosis are limited. To date, few attempts have been made to identify CFPs from $M$. tuberculosis applying 2DE (11, 13, 19).

Currently used protocols like ammonium sulphate precipitation, lyophilisation and concentration of filtrate using membranes are time consuming. Furthermore, high salt concentration after these procedures can pose a problem to the integrity of the isoelectric focusing (IEF) gel (a step of 2DE) (9). Therefore, salt removal is a necessary step before or after these procedures. Due to these tedious procedures used for preparation of CFPs complete overview of the secretory components of various clinical isolates of M. tuberculosis is difficult to obtain. Protein precipitation with trichloroacetic acid (TCA) is known as the preferred method for sample preparation from cell extracts of mycobacteria $(4,20)$. A recent 
study showed an improved sample preparation from cell extracts of Mycobacterium bovis BCG using SDS prior to TCA precipitation (1). The present study shows the utility of this improved method after slight modification for CFPs of Mycobacteria, which might present a basis for extensive work on secretory proteins of $M$. tuberculosis.

Clinical isolates of $M$. tuberculosis were inoculated (approx $10^{8} \mathrm{CFU} / \mathrm{ml}$ ) in tween-80 free Sauton's medium and incubated at $37^{\circ} \mathrm{C}$ for 5 weeks (late log phase) on a shaking incubator.

The cultures were centrifuged at $18,000 \mathrm{~g}$ for $30 \mathrm{~min}$ at $4^{0} \mathrm{C}$ and sequentially filtered through $0.45 \mu \mathrm{m}$ membrane followed by $0.22 \mu \mathrm{m}$ Millex GV PVDF membrane (Millipore, Bedford, MA, USA). Resulting filtrate was divided into three equal (200 $\mathrm{ml}$ ) volume for each sample. Sample 1 of culture filtrate was then precipitated after slight modification of previous reported method (1). Briefly, 10\% SDS (Sigma, St. Louis, USA) was added to obtain $0.1 \%$ final concentration $(\mathrm{w} / \mathrm{v})$ in the culture filtrate $(\mathrm{CF})$ and kept in a boiling water bath for $5 \mathrm{~min}$. CF was treated with trichloroacetic acid (TCA, w/v) (Sigma, St. Louis, USA) to obtain final concentration $10 \%$ (w/v). Finally, this mixture was incubated at $-20^{\circ} \mathrm{C}$ for $5 \mathrm{hrs}$ and the resulting precipitate was removed by centrifugation at 18,000 $\mathrm{g}$ for 30 min at $4^{0} \mathrm{C}$. Minimum volume of HPLC grade water (Qualigens Fine Chemicals, Mumbai, India) was added to disperse the pellet and then the whole suspension was washed with $1 \mathrm{ml}$ of pre-chilled acetone (Sigma, St. Louis, USA). Sample 2 was precipitated by Ammonium sulphate (Sigma, St. Louis, USA) as described elsewhere but without dialysis (12). Sample 3 was subjected to ammonium sulphate precipitation after SDS treatment as described above. Air dried pellets were dissolved in minimum volume of 2D rehydration buffer (Bio-Rad Laboratories, Hercules, CA, USA). The protein concentration was determined by Bradford's method (Sigma, St. Louis, USA) (2).

Isoelectro focusing (IEF/ $\mathrm{I}^{\mathrm{st}}$ dimension) was performed as described earlier (6). Briefly, $100 \mu \mathrm{g}$ protein in rehydration buffer was applied to $7 \mathrm{~cm}$ IPG strips (Bio-Rad Laboratories, Hercules, CA, USA) of $\mathrm{pH} \mathrm{4-7} \mathrm{and} \mathrm{rehydrated} \mathrm{for} 16 \mathrm{hrs}$ at $20^{\circ} \mathrm{C}$. The strips were then focused on an IEF cell (Bio-Rad Laboratories, Hercules, CA, USA) using the following parameters :(i) $0-250 \mathrm{~V}, 1 \mathrm{hr}$ (ii) $250 \mathrm{~V}, 1.5 \mathrm{hr}$ (iii) 250$3000 \mathrm{~V}, 4 \mathrm{hr}$ and (iv) $3000 \mathrm{~V}$ constant until $15 \mathrm{kVhr}$, at $20^{\circ} \mathrm{C}$. The current limit was $50 \mu \mathrm{A} / \mathrm{IPG}$ strip. After completion of the Ist dimension run, each strip was equilibrated for $10 \mathrm{~min}$ with equilibration buffer I and then with equilibration buffer II (BioRad Laboratories, Hercules, CA, USA). The second dimension run was carried out by placing IPG strips on $12 \%$ SDS-PAGE gels (10) and sealed with $1 \%(\mathrm{w} / \mathrm{v})$ agarose in electrode buffer. Protein spots were visualized by staining with coomassie brilliant blue R-250 (Sigma, St. Louis, USA). This 2DE was carried out using three different clinical isolates of $M$. tuberculosis. The results obtained by this sample preparation method is reproducible in independently obtained culture filtrates of the same clinical isolate of $M$. tuberculosis collected from the same growth phase. In the present study 5 weeks of culture filtrates were collected, therefore contamination with intracellular proteins may be expected. All the experiments were carried out two times.

Mycobacterial proteins secreted in liquid media are known as important targets for early diagnosis of tuberculosis as well as candidates for protective immunity $(14,15)$. Efforts have been directed to characterize CFPs of M. tuberculosis $(13,16$, 20). Recently a group from our institution reported that addition of SDS prior to TCA precipitation of Mycobacterial cell extract proteins increases the resolution of the $2 \mathrm{DE}$ gel pattern (1). Our study was designed to explore the utility of this procedure after minor modifications for preparation of the samples for 2D analysis from CFPs of M. tuberculosis.

Sample preparation is a crucial factor in 2DE which needs complete solubilisation and denaturation of sample proteins. In an ideal procedure of sample preparation time should be kept as short as possible to avoid protein modifications and losses. A series of studies on CFPs were done using Ammonium sulphate precipitation $(13,16)$, lyophilisation and concentration by membranes etc (20). All these techniques are not themselves complete; require a desalting method like dialysis, which can further dilute the sample. Practical removal of a dialyzable 
component from the parent sample cannot be accomplished without changing the dialysis buffer at least once (may be up to 3 times). Moreover, these procedures are time consuming and laborious. Therefore, all these traditional techniques are complicated, and due to multistep procedures, proteins present in low quantity may be lost. Hence, prepared samples may vary with each revision and result in poor reproducibility of $2 \mathrm{DE}$.

Lyophilisation is a well known technique and can be helpful to concentrate a sample. According to the volume of the solution it may take from two hrs to overnight and dialysis is a necessary step during this procedure. Similarly high salt may remain during concentration while using a membrane without dialysis and can be deleterious for excretory-secretory proteins (13). This high salt concentration can lead to zones of dehydration in the gel which results in loss of current within the strip. This may cause poor resolution, streaking and overlapping of the protein spots. Our experiment with ammonium sulphate precipitation without dialysis reveals the same (Figure 1A). Culture filtrates prior to ammonium sulphate precipitation were also treated with SDS because the increased resolution of cell extracted proteins in TCA method was reported with this detergent in a previous study (1) of our groups, but no improvement was observed in ammonium sulphate precipitation after pre treatment with SDS (figure not shown).

SDS-TCA method is comparatively simple, rapid and inexpensive compared to other traditional methods used for $2 \mathrm{D}$ sample preparation from $\mathrm{CF}$. Our study using this procedure shows greater resolution (Figure 1B and 1D) in comparison to ammonium sulfate method of protein precipitation (Figure 1A) without any additional time consuming step like dialysis. The addition of SDS to mycobacterial culture filtrate prior to TCA precipitation improves the resolution of 2D-gels (Figure 1B and 1D) as described previously for mycobacterial cell extracts (1). Mycobacteria have high lipid contents, which may bind to proteins during sample preparation and can change both their isoelectric point (pI) \& molecular weight (MW), furthermore lipid can also hinder the isoelectro focusing (IEF) run. Therefore, delipidation is a very essential step prior to $2 \mathrm{D}$ run. Washings with acetone in this procedure are useful to remove the lipids. Addition of SDS increases the solubility of proteins (21). The enhanced resolution of certain proteins shown in magnified gel sections (Figure $1 D_{1}, 1 D_{2}$ and $1 D_{3}$ ) validates it. An increase in the number of protein spots was observed after solubilization of Fasciola hepatica whole sample with hot SDS (9). Further, boiling of the sample along with SDS, as well as precipitation with TCA inhibits protease activities which results in a better recovery of proteins (5). Moreover, without any additional time consuming steps like dialysis etc., the chances of protein modifications and losses can be minimized. Hence, the good resolution of protein spots can be noted with this rapid procedure. Finally, the SDS-TCA precipitation approach could be a valuable contribution for more studies using CFPs of clinical isolates of M. tuberculosis.
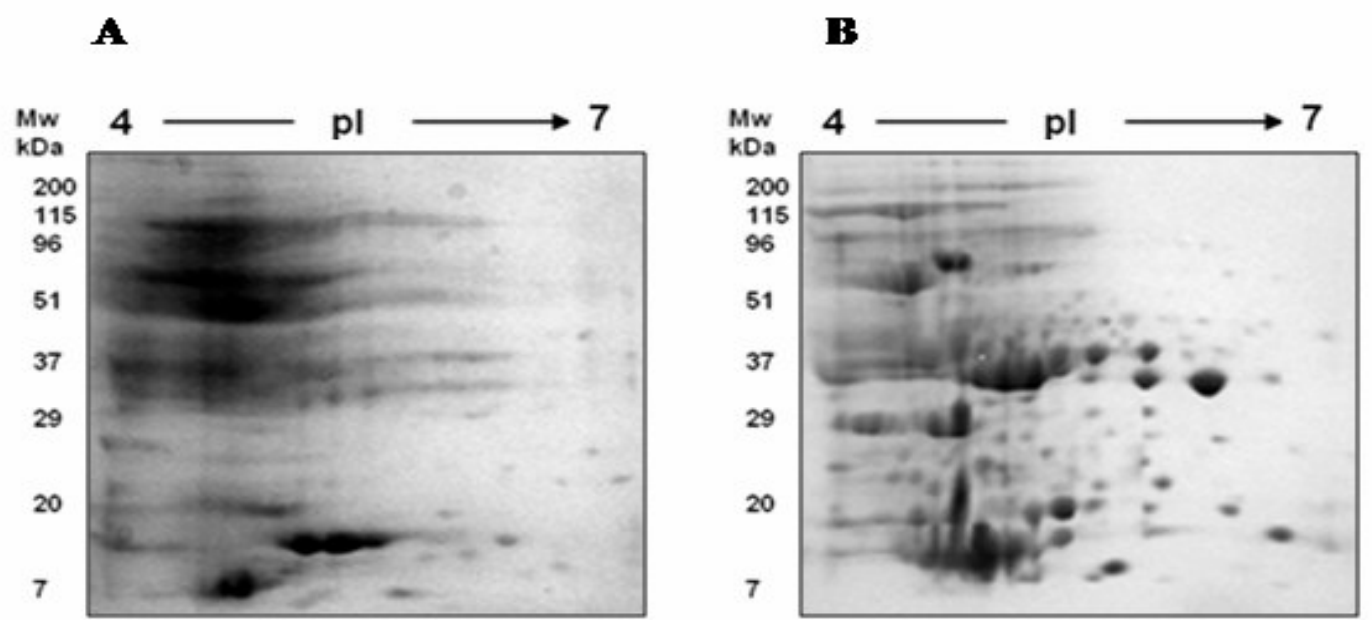

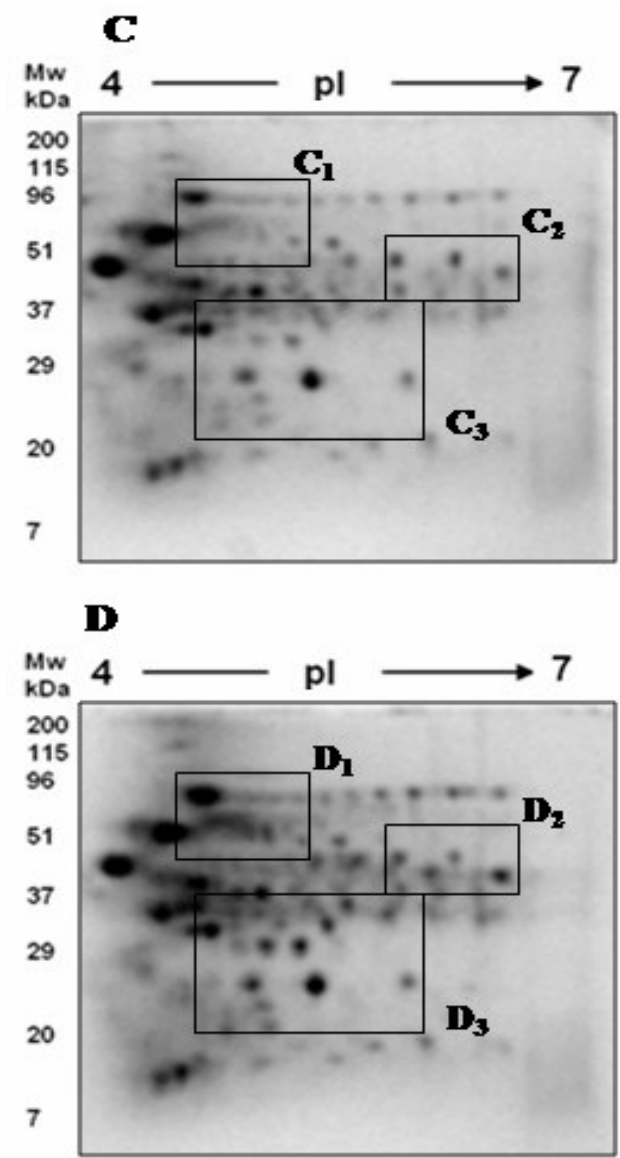

(C)

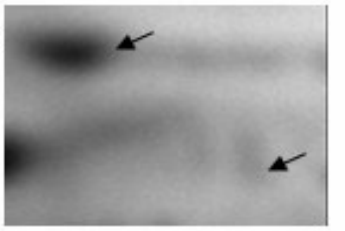

(D)

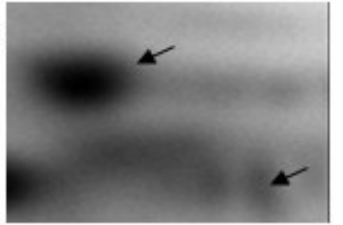

$\left(\mathbf{C}_{\mathbf{z}}\right)$

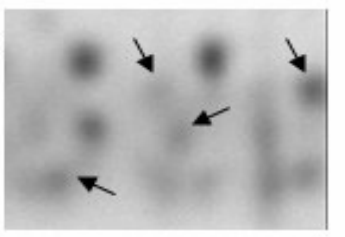

( $\left.\mathbf{D}_{2}\right)$

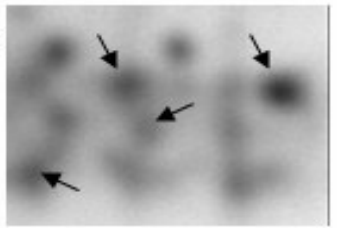

(C)

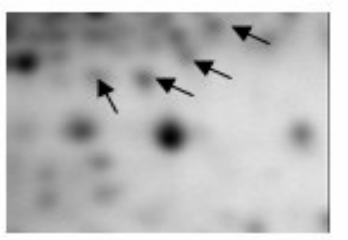

(D)

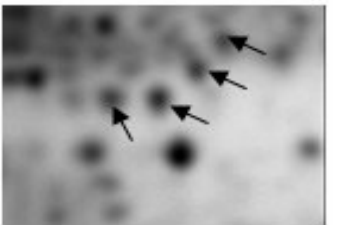

Figure 1. 2DE gel of culture filtrate proteins from M. tuberculosis. A) sample preparation from clinical isolate by ammonium sulphate precipitation without dialysis, B) sample preparation from clinical isolate by SDS-TCA procedure without dialysis, C) sample preparation from H37Rv by using TCA without dialysis, D) sample preparation from H37Rv using SDS-TCA procedure without dialysis. C1-C3 and D1-D3 magnified section of gel and arrows showing difference in resolution.

\section{ACKNOWLEDGEMENTS}

Authors sincerely thank Ms Itu Singh, SRF and Ms Chanchal Jain, Project Assistant for their help in writing this manuscript. GK is thankful to CSIR-UGC, New Delhi for providing fellowship. DBT, New Delhi (BT/PR/6959/Med/ 14/913/2005) is acknowledged for funding this study.

Authors declare that they have no conflict of interests in the present study.

\section{REFERENCES}

1. Bisht, D.; Singhal, N.; Sharma, P.; Venkatesan, K. (2007). An improved sample preparation method for analyzing Mycobacterial proteins in twodimensional gels. Biochemistry (Moscow), 72, 672-674.

2. Bradford, M.M.( 1976). A rapid and sensitive method for the quantitation of microgram quantities of protein utilizing the principle of protein-dye binding. Anal. Biochem., 72, 248-254.

3. Dunbar, B.S. (1987). Two-dimensional electrophoresis and immunological techniques. Plenum press, New York, pp. 8-15.

4. Gazdik, M.A.; McDonough, K.A. (2005). Identification of cyclic AMPregulated genes in Mycobacterium tuberculosis complex bacteria under low-oxygen conditions. J. Bacteriol., 187, 2681-2692.

5. Gorg, A.( 1999). IPG-Dalt of very alkaline proteins. Meth. Mol. Biol., $112,197-209$

6. Gorg, A.; Obermaier, C.; Boguth, G.; Harder, A.; Scheibe, B.; Wildgruber, R.; Weiss, W.( 2000). The current state of two-dimensional electrophoresis with immobilized $\mathrm{pH}$ gradients. Electrophoresis, 21, 1037-1053. 
7. Hirano, H. (1989). Microsequence analysis of winged bean seed proteins electroblotted from two-dimensional gel. J. Prot. Chem., 8, 115-130.

8. Hubbard, R.D.; Flory, C.M.; Collins, F.M.( 1992). Immunization of mice with mycobacterial culture filtrate proteins. Clin. Exp. Immunol. 87, 9498.

9. Jefferies, J.R.; Brophy, P.M.; Barrett, J. (2000).Investigation of fasciola hepatica sample preparation for two-dimensional electrophoresis. Electrophoresis, 21, 3724-3729.

10. Laemmli, U.K. (1970). Cleavage of structural proteins during the assembly of the head of bacteriophage T4. Nature (London), 227, 680685

11. Malen, H.; Berven, F.S.; Fladmark, K.E.; Wiker, H.G. (2007). Comprehensive analysis of exported proteins from Mycobacterium tuberculosis H37Rv. Proteomics, 7, 1702-1718.

12. Nagai, S.; Wiker, H.G.; Harboe, M.; Kinomoto, M. (1991). Isolation and partial characterization of major protein antigens in the culture fluid of Mycobacterium tuberculosis. Infect. Immun., 59, 372-382.

13. Pheiffer, C.; Betts, J.C.; Flynn, H.R.; Lukey, P.T.; van-Helden, P. (2005). Protein expression by a Beijing strain differs from that of clinical isolate and Mycobacterium tuberculosis H37Rv. Microbiology, 151, 1139-1150.

14. Roberts, A.D.; Sonnenberg, M.J.; Ordway, D.J.; Furney, S.K.; Brennan, P.J.; Belisle, J.T.; Orme I.M. (1995). Characteristics of protective immunity engendered by vaccination of mice with purified culture filtrate protein antigens of Mycobacterium tuberculosis. Immunology, 85, 502508 .
15. Samanich, K.M.; Keen, M.A.; Vissa, V.D.; Harder, J.D.; Spencer, J.S.; Belisle, J.T.; Zolla-Pazner, S.; Laal, S. (2000). Serodiagnostic potential of culture filtrate antigens of Mycobacterium tuberculosis. Clin. Diagn. Lab. Immunol., 7, 662-668.

16. Sartain, M.J.; Slayden, R.A.; Singh, K.K.; Laal, S.; Belisle, J.T. (2006). Disease state differentiation and identification of tuberculosis biomarkers via native antigen array profiling. Mol. Cell. Proteomics, 5, 2102 - 2113.

17. Shaw, M.M.; Riederer, B.M. Sample preparation for $2 \mathrm{D}$ gel electrophoresis. (2003). Proteomics, 3, 1408-1417.

18. Siddiqui, S.M.; Orme, I.M.; Saxena, R.K. (2000). Efficacy of culture filtrate protein preparations from Indian isolates of M. tuberculosis to activate $\mathrm{T}$ cells derived from healthy donors. Int. J. Tuberc. Lung. Dis., 4, 980-987.

19. Sonnenberg, M.G.; Belisle, J.T. (1997). Definition of Mycobacterium tuberculosis culture filtrate proteins by two-dimensional polyacrylamide gel electrophoresis, $\mathrm{N}$-terminal amino acid sequencing, and electrospray Mass Spectrometry. Infect. Immun., 65, 4515-4524.

20. Starck, J.; Kallenius, G.; Marklund, B.I.; Andersson, D.I.; Akerlund, T. (2004). Comparative proteome analysis of Mycobacterium tuberculosis grown under aerobic and anaerobic conditions. Microbiology, 150, 38213829 .

21. Wessel, D.; Flugge, U.I. (1984). A method for the quantitative recovery of protein in dilute solution in the presence of detergent and lipids. Anal. Biochem., 138, 141-143. 